\title{
Accessibility of Essential Amino Acids, Synthesis of SARS-CoV-2 Virus Polyproteins, and the Outcomes of COVID-19 Pathogenesis
}

Sophia V. Ponomarenko

SophiGen, Germany

For contacts: Sophia Ponomarenko, e-mail: ponomarenko@t-online.de; Tel. (49) 1628491717

\begin{abstract}
Summary
Aim. To identify: a risk factor influencing the development of COVID-19 disease. Compare the amino acid composition of animal and plant proteins with non-structural polyproteins of the SARS-CoV-2 virus. To analyze: the impact of dietary essential amino acids (EAAs) on the development of infectious disease COVID-19.
\end{abstract}

Materials and methods. The scientific data and information needed for this analysis was found in publications and media available on the Internet, as well as taken from statistical databases, using the necessary keywords for a single tag or in various combinations of them. Statistical samples were formed from sources and facts available on the Internet. Amino acid sequences of proteins were obtained from databases (https://www.ncbi.nlm.nih.gov/, https://www.uniprot.org/uniprot/). Results and discussion. Analysis of statistical data and assessment of nutritional factors during the development of the 22-month pandemic in different countries indicated that the outcome of COVID-19 disease was aggravated by excessive consumption of animal proteins. The number of reported cases of SARS-CoV-2 virus (RPr) infection and deaths (IFR) from COVID-19 disease per one thousand inhabitants was significantly lower in regions that consumed predominantly plant-based foods minimal in EAAs. A positive relationship was found between the pathogenicity of SARS-CoV-2 and the amount of animal proteins ingested, with correlation coefficients $r=0.83$ for $\mathrm{RPr}$ and $\mathrm{r}=0.61$ for IFR. Human coronaviruses contain much more EAAs than cellular organisms. Edible plant proteins contain 2-3 times less leucine, lysine, and especially threonine and valine (LKTV) than SARS-CoV-2 polypeptides. Optimal synthesis of the SARS-CoV-2 virus Pp1a polyprotein requires timely a large amount of these four EAAs.

Conclusions. The limit of EAAs in food can be a competitive metabolic factor that reduces or inhibits the rate of intracellular synthesis of nonstructural polyproteins of SARS-CoV-2 virions. Deficiency of EAAs, especially free valine and threonine, can suppress the early translation of SARS-CoV-2 virus proteins. A diet low in EAAs and especially LKTV may prevent rapid, highly productive viral replication and pathogenic development of COVID-19.

KEYWORDS: animal proteins; coronavirus SARS-CoV-2; COVID-19; diet; essential amino acids; infection; pandemic; pathogenesis; polyprotein; protein synthesis; risk factor

Conflict of interest: The author declares that she has no commercial or non-profit associations that could cause a conflict of interest in connection with the published manuscript.

Abbreviations: AAs - Amino Acids, ACE2 - membrane bound Angiotensin-Converting Enzyme 2, BCAA - Branched-Chain Amino Acid, EAAs - Essential Amino Acids, FAAs - Free Amino acids, gRNA - genomic RNA, HCoV - Human CoronaViruses, IFR - Infection Fatality Rate, Km - Michaelis-Menten coefficient, LAAs - Limited Amino Acids, LKTV Leucine+Lysine+Threonine+Valine, NTP - nucleoside triphosphate, Pp1a and Pp1ab Polyproteins, PT2 Pneumocytes Type 2, rER - rough Endoplasmic Reticulum , RPr - Rate of Prevalence, SARS - Severe Acute Respiratory Syndrome, cSME - Spike, Membrane and Envelope proteins-lipid complex, WHO - World Health Organization, 


\section{Introduction}

Coronavirus SARS-CoV-2 was discovered two years ago and the COVID-19 pandemic caused by it blocks almost all aspects of human activity [1-2]. Unfortunately, there is no etiotropic or highly effective drug blocking the replication cycle of the SARS-CoV-2 virus yet, and a radical decrease in infection dynamics has not been observed globally [1-5]. Humanity will fight the SARS-CoV-2 virus infection and the consequences of the pandemic for another year or more in various ways. Numerous studies have shown that social isolation, sanitary measures and vaccination help fight the virus. Comorbidities, advanced age, obesity or dangerous malnutrition are risk factors for the severity of COVID-19 [1-2].

The importance of nutrition in the outcome of COVID-19 has been explored in dozens of research programs across countries and populations. Numerous studies on the effect of diet on COVID-19 outcomes have been published in more than two thousand articles, which allowed data to be processed and analyzed in systematic and other reviews [6-13]. Diet type has also been shown to be one of the important socio-economic factors for the development of the pathogenic process of the virus, and it has been demonstrated that the consumption of excess fat, sugar and protein is linearly correlated with the severity of COVID-19 disease and mortality [14-15]. Excessive consumption of animal proteins is a serious factor in many health problems [16] and a risk of severe development of SARS-CoV-2 as well [14-15]. It has been shown that adequate consumption of plant proteins correlates with a low incidence of negative manifestations of the infectious pathogenesis of the SARS-CoV-2 virus [15,17].

Optimal interaction with its host is fundamental to a successful viral replication cycle. The development of COVID-19 infection depends on the level of biochemical interaction between the virus and the host. The pathogen has been shown to destabilize proteostasis and amino acid homeostasis [18-23]. Viruses use intracellular mechanisms and building resources for productive replication. When the body is unable to supply enough nutrients to synthesize the necessary viral proteins, pathogen replication slows down or is interrupted. Therefore, the type of diet is one of the key factors in the development and outcome of the infectious disease COVID-19.

The amount of the synthesized viral protein after the invasion of the pathogen into the cell increases successively passing through the lag phase, the rapid growth phase, and the exponential phase [19,23-25]. In the rapid growth phase and especially in the exponential phase, viral replication requires a high availability of substrates for biosynthetic reactions. For such a high rate of protein synthesis of the SARS-CoV-2 virus, the concentration of limiting amino acids (LAAs) should be much higher than $\mathrm{Km}$.

To elucidate the mechanism of the influence of dietary proteins on the development of SARSCoV-2 virus pathogenesis, it is necessary to analyze the biochemical and molecular biological aspects of metabolism during the host/pathogen interaction. The ability to influence the development of the epidemic process of SARS-CoV-2 with the help of diet is a very applicable, easily accessible and cheap method of combating the current pandemic of COVID- 19.

\section{Results and discussion}

\section{Characteristics of the development of the COVID-19 pandemic over 2 years}

The pathogenic SARS-CoV-2 virus was discovered two years ago. In around 700 days (Monday, January 31, 2022), after the announcement of the COVID-19 pandemic by WHO [1], there were about 380 million patients globally infected with the SARS-CoV-2 virus, which amounted to approximately $5 \%$ of the world's population. By this time, the current COVID-19 pandemic had entered its sixth wave of infections and deaths [3]. WHO experts have identified three groups of patients infected with the virus, depending on the development of the disease [1-2]. Patients in the largest group had the infection with mild or no symptoms; the next group includes patients with severe disease, and 5\% of COVID-19 disease developed to a critical phase with a high mortality rate. To date, about 300 mio people (79\% of infected people) have recovered from the disease, approximately 5.7 mio infected (1.5\%) died [3]. 
Data on the consequences of the infectious disease COVID-19 vary significantly between different continents, states and even distinct regions in the same country $(1-3,14)$. Three countries: the United States of America (USA), India and Brazil have recorded the most infections and deaths from COVID-19. These three countries were home to $38 \%$ of the globally infected and $37 \%$ of all deaths. More than one-fifth of those infected, with a death rate $16 \%$ of all global cases, were registered in the USA.

North America has the highest number of registered infections per capita (RPr) about $22.8 \%$ and number of registered COVID-19 deaths (IRF) $0.27 \%$ in the USA. On the other hand, in some European countries, RPr exceeded 35\%, which is 6-7 times higher than the global average. In Peru, the IRF was over $0.6 \%$, roughly an order of magnitude higher than the global average $(0.07 \%)$. China has the lowest infection and mortality data from COVID-19 in Asia. There, the RPr indicator is 3 thousand times, and the IRF is 240 times lower than the world average. Since the emergence of new variants of the virus remains a potential cause for the further development of the epidemic, a dangerous increase in COVID-19 cases and deaths is possible in the coming months if drastic measures are not taken to combat the SARS-CoV-2 virus.

\section{Related molecular biological characteristics of the SARS-CoV-2 virus}

The SARS-CoV-2 virus belongs to the Coronaviridae family, the Betacoronavirus genus and the Sarbecovirus subgenus. Betacoronaviruses are the largest and most developed RNA viruses; their genome type is designated NSss + RNA, since they have an unsegmented single-stranded positive-sense RNA. Coronaviruses that cause disease in humans are referred to as HCoV. The linear genomic RNA (gRNA) of coronaviruses is about $30 \mathrm{~kb}$ in size and protected by a developed spiral capsid [26-31].

Infection with the SARS-CoV-2 virus causes acute respiratory syndrome (SARS) in humans, and the WHO has named this disease COVID-19 [1]. The SARS-CoV-2 virus has been systematically studied using genetic, biochemical, molecular biological and other methods [26-29]. This virus has molecular genetics and biological characteristics similar to other coronaviruses, namely, it is narrowly specific, has a spherical shape about $100 \mathrm{~nm}$, is complexly organized and is surrounded by a bilayer lipid membrane [26-30]. One of the earliest published genomes of the null variant of the hCoV-19 / Wuhan / IVDC-HB-01/2019 virus has a genome size of 29.9 thousand nucleotides [28]. As an obligatory parasite, the virus uses an intracellular apparatus for the synthesis and posttranslational modifications of all the necessary polypeptides, as well as RNA molecules. The remaining components that make up the structure of pathogenic virions are taken from the host cell [26-30].

The genetics, structure, and function of SARS-CoV-2 proteins are well studied and discussed in numerous publications, as well as detailed in several reviews [27-31]. Large databases of the sequence, structure and function of coronavirus proteins have been created [32-33]. It is believed that few of the viral proteins can be the subject of vaccines or targeted inhibitors [30-31]. Epitopes of surface proteins are the first objects in the immunological response of the body, and potential candidates for the design of vaccines.

The virus has no storage proteins, so all proteins are needed for its rapid reproduction. The genome of coronaviruses encodes the synthesis of structural and functional polypeptides [27-31]. The functional open reading frame ORF1ab is located in the 5'-genomic region from 268 to 21555 nucleotides of the SARS-CoV-2 virus [29-33] and contains 16 nsp genes encoding 16 nonstructural proteins (NSPs). This ORF makes up approximately two-thirds of the viral genome. It encodes the production of two, primarily and rapidly translated, polyproteins Pp1a and Pp1ab [2934]. These two polypeptides are synthesized directly upon invasion from using gRNA as template. The Pp1a polypeptide is expressed 1.4-2.2 times faster than Pp1ab [29-30]. This is a cotranslational result of a programmed -1 ribosome frameshift common to coronaviruses [35]. Eleven NSPs, from the nsp1 to nsp11 genes, are released from the Pp1a polyprotein, and fifteen protein types: nsp1-10 plus nsp12-16 are released from Pp1ab after post-translational proteolytic cleavage [29, 31-33]. 
As in other HCoVs, four genes encoding structural proteins: spike (S), envelope (E), membrane $(\mathrm{M})$, and nucleocapsid (N) are located in the 5' to 3' direction of the remaining third of the SARSCoV-2 genome. These genes border on a variable number of accessory proteins (ORFs) [27-31]. The intensively studied spike protein is the largest structural polypeptide containing 1273 amino acid residues [30-33]. The spike protein consists of two subunits $\mathrm{S} 1$ and $\mathrm{S} 2$ and is responsible for precise attachment, fusion of SARS-CoV-2 with host cell membranes, and endocytosis. This glycoprotein forms spikes on the membrane surface about $10 \mathrm{~nm}$ in size [36]. The $\mathrm{S}$, E, and $\mathrm{M}$ proteins associated with the viral membrane provide the structural and functional properties of the viral envelope. The nucleocapsid protein $\mathrm{N}$ is synthesized in the cytoplasm and, together with the gRNA molecule of the SARS-CoV-2 virus, forms a capsid with a helical symmetry type. The three structural polypeptides S, E and $\mathrm{M}$ are overexpressed on rER and, after translation, are folded and processed in these organelles. Accessory polypeptides are not structural; they are synthesized and processed in the cytoplasm [30-31].

Spike polypeptides are synthesized at a higher rate than other structural proteins [34] and form glycosylated trimers after folding. They, in combination with the $\mathrm{M}$ and E proteins, are released from rER and then form a specific protein-lipid complex (cSME) with the membranes of the Golgi apparatus [30-31]. N-proteins associate with newly synthesized gRNAs in the cytoplasm forming many densely condensed nucleocapsids (protovirions). Protovirions bind to membrane cSME secreted from the Golgi apparatus to form self-organized virion progeny [27-29]. Mature progeny virions attach to the cell membrane and are released during exocytosis, their number can reach $10^{3}$ per cell [36].

Viruses, as obligate parasites, exist in two forms: extracellular and vegetative. The complete productive cycle of a virus consists of the main phases: infection, replication, release and transmission of virions. Replication of the SARS-CoV2 virus, after its endocytosis and fusion with the cell, occurs in several stages, namely: the formation of uncoated and protected replication-transcriptional complexes (RTCs); biosynthesis of structural and non-structural viral components (proteins and RNA); the formation of protovirions; maturation and assembly of progeny virions for their release from the cell [27-29].Viral gRNA should primarily translate the non-structural polypeptides Pp1a and Pp1ab using cellular ribosomes. Since these polypeptides produce the enzymes necessary for replication and transcription of the genomic and subgenomic RNA of the coronavirus [30-31]. The total length of Pp1ab in the SARS-CoV2 virus is 7096 amino acid residues, and the pp1a polypeptide consists of 4455 amino acid residues [32-33]. About $85 \%$ of the virus gRNA nucleotides encode Pp1ab and the spike protein.

\section{Type of diet influences the development of COVID-19 disease}

Animals need essential macronutrients (proteins, carbohydrates and lipids) to sustain their life, health and reproduction. The WHO has long promoted recommendations for healthy eating. Human food must contain the required quantity and quality of basic products and additional nutrients $[1,16,37]$. The most commonly used staples are: rice, wheat, corn, beans. However, plants are incomplete sources of protein due to their low content of one or more essential amino acids (EAAs). To achieve the optimal EAAs combination, vegans are advised to consume additional sources of protein. The diet of many people in some countries or regions is low in calories, uniform, and does not contain the recommended complete protein [1,14-15,38-39]. WHO and the Food and Agriculture Organization (FAO) of the United Nations have recommended the optimal amount of dietary protein and the correct ratio of EAAs [37] to maintain quality of life and good health. Protein bioavailability is a criterion for determining the nutritional value of foods [37].

As noted above, diet can significantly influence the development of COVID-19 [6-15]. In large statistical samples, it has been shown that the severity of COVID-19 was worsened by the consumption of animal proteins in excess of the WHO recommendations [14-15]. In contrast, a plant-based diet is directly correlated with mild SARS-CoV-2 infection process $[15,17]$. 
These data were confirmed when comparing the statistical sample for the top 20 countries in terms of the number of infected people (Table S1). The correlation coefficients between animal protein intake and pathogenicity of SARS-CoV-2 vary between 0.83 for infection rate and 0.61 for specific mortality (Table S1). The correlation coefficients between the development of COVID-19 and the consumption of plant foods are lower than in studies conducted before the fifth global wave of the pandemic [14-15], which analyzed epidemiological data from a different type of statistical samples. The resulting correlation coefficients (Table S1) confirm that overconsumption of animal proteins correlates with the severity of COVID-19. It can be assumed, that certain components of dietary animal proteins are critical factors to the development and outcome of COVID-19 disease.

\section{Comparison of the amino acid composition of proteins from animals, plants and viruses}

Proteins and their AAs are essential for the structure and function of living cells and viruses. The building blocks of proteins are amino acid residues. Therefore, it is logical to study the dependence of the severity of COVID-19 on the AAs amount and composition of proteins consumed. The significance of viruses' amino acid profile is analyzed here.

Biochemists divide the 20 standard proteinogenic AAs into two groups depending on the ability of the human body to synthesize them: non-essential (NEAAs) and essential. The nine EAAs must come from food, the rest are synthesized in various cells of the body.

Edible products differ in content of NEAAs and EAAs. Animal products contain more EAAs than plants [40-42]. Fish and eggs on average contain about 44\% EAAs, milk and meat - 43\% (Tab. 1, Fig. 1). In the proteins of the main products produced from plants: rice, wheat, potatoes and soybeans, the proportion of EAAs is $37 \%, 30 \%, 35 \%$ and $38 \%$, respectively (Fig. 1, Table 1). An adult should consume $0.8-1 \mathrm{~g}$ of protein per $\mathrm{kg}$ of body weight daily $[1,37]$ and $0.2 \mathrm{~g} / \mathrm{kg}$ BW/day EAAs [43]. In Europe and America, people consume much more total and animal protein (Western diet) (Table 2, Fig. 2) than the WHO recommends [1,14-15,38-39]. More than half of the EAAs consumed are represented by four amino acids: leucine, lysine, threonine and valine (LKTV). Their content in food varies greatly depending on the diet. Plant proteins contain much less EAAs (Fig. 1-3, Tables 1-2) and have a particularly low content of lysine [40-42]. Therefore, vegan diets contain much less EAAs and LKTV than meat eaters or the USA standard diet [44] (Table 2., Fig. 2). The proteins of the standard American diet contain almost twice as many LKTV amino acids [44-46] as in the vegan diet (Table 2.). Children generally require more dietary protein per kg of body weight than adults, and the elderly get by with less. WHO recommends the amount of total protein and AAs required per day (Table 2, Fig. 2) for optimal body functioning in children and adults $(1,37)$. However, residents of many countries in Africa and Asia consume much less total protein, and especially little animal protein [1,14-15,38-39].

Table 1. Ratio of total EAAs and LKTV of animal or vegetable based proteins in staple food Amount of total EAAs and LKTV in \% in meat (from beef, chicken and pork), egg-milk products and diet plants [40].

\begin{tabular}{lccccccc} 
Amino acid & Meat & Egg-milk & Salmon & Wheat & Rice & Potato & Soybeans \\
Leucine & $8,0-8,2$ & $8,5-8,8$ & 8,6 & 6,7 & 8,28 & 6 & 7,7 \\
Lysine & $8,8-9,1$ & $7,2-7,8$ & 9,4 & 2,2 & 3,66 & 6 & 6,2 \\
Threonine & $4,2-4,6$ & $4,0-4,8$ & 4,4 & 3 & 3,59 & 3,6 & 4,2 \\
\hline Valine & $5,2-5,4$ & 6,0 & 5,2 & 4,4 & 6,14 & 5,5 & 4,6 \\
\hline Sum LKTV & $31,0-33,0$ & $30,5-32,8$ & 32,4 & 19,8 & 25,97 & 25,3 & 27,3 \\
Total EAAs & $41,8-44,3$ & $42,9-43,7$ & 43,8 & 30,2 & 37 & 35 & 38,5
\end{tabular}




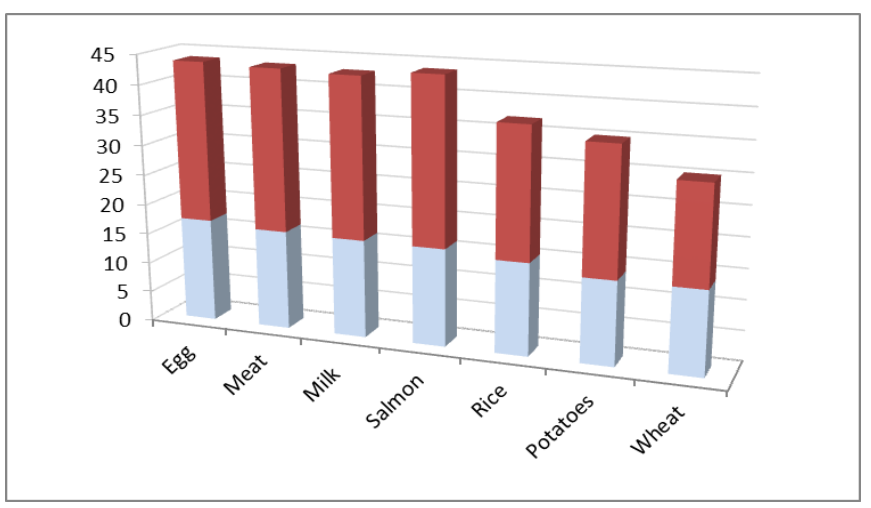

Fig.1. Content of total EAAs and LKTV in animal or vegetable dietary proteins

Ratio of total EAAs and LKTV (red), \% of total protein, in egg, meat (mean from beef, chicken and pork), milk products, rice, potato and wheat [40]. On the ordinate axis indicated amount of AAs as percentage of the total protein.

\section{The concentration of amino acids in the blood}

Amino acids from hydrolyzed dietary proteins are absorbed in the intestine and transported into the bloodstream [47-50]. The concentration of each AA in the blood plasma varies widely both in normal conditions (Table 3 ) and in various pathologies [43,45,47,51-54]. Their concentration in the blood and other tissues may depend on many factors, but is successfully regulated in a healthy body [37]. The content of free AAs in the bloodstream changes during the day and can significantly increase after a meal [37,48-50]. Free amino acid (FAA) homeostasis is maintained through synthesis/degradation of polypeptides and amino acids, protein proteolysis, AAs uptake from the gut into the bloodstream, and their utilization in various tissues [37,47,50,53-56]. Baseline (fasting) plasma concentrations of some FAAs are lower in vegans [45,55] than those who consume animal products (Table 3). The content of EAAs in human muscles is lower than in the proteins of other mammals (Fig. 3). The level of all FAAs and especially EAAs in plasma increases 2-3 times after a meal [44,48-50,55,57-58], therefore their transport to organs and tissues rises $[48,58]$. This leads to an intensification in the rate of protein synthesis $[48-49,57,59]$ and is used by athletes to build muscle mass. An adult synthesizes $3 \mathrm{~g}$ of protein per $1 \mathrm{~kg}$ of body weight per day [37].

The SARS-CoV-2 virus modifies the consumption profile and distribution of proteins and AAs in host cells. The pathogen alters central cellular pathways such as translation, splicing, carbon metabolism, protein homeostasis (proteostasis) and nucleic acid metabolism [19,60]. The serum metabolome of COVID-19 patients is distinctive and has important value in investigating pathogenesis, determining a diagnosis, predicting severe cases, and improving treatment [61]. The development of a viral infection leads to an imbalance in the metabolism of AAs in the body $[21,23,37,43,51,54]$. Composition of AAs in patients' plasma can vary significantly depending on the severity of COVID-19 [20-23,51,62]. About 70\% of the three BCAAs: leucine, isoleucine and valine are transported from the bloodstream to peripheral tissues [52] and their metabolism is regulated coordinately. BCAAs are essential for the regulation of anabolic process; their transport is interdependent with other AAs [22]. Leucine rapidly accelerates protein synthesis [48,57$58,63]$.

\section{Peculiarity of AAs composition of virus polypeptides}

Virus polypeptides are very different from human proteins, other animals or plants in terms of the amount of EAAs and their proportion in the total protein. Edible parts of plants contain much less EAAs than animals (Table 1., Fig. 2-3). The proportion of EAAs in human Betacoronavirus $(\mathrm{HCoV})$ proteins is much higher than in mammalian tissues (Fig. 1-3). The proteins of the $\mathrm{HCoV}-$ HKU1 coronavirus contain the highest amount of EAAs, and the SARS-CoV2 virus contains more of the four amino acids LKTV compared to other HCoVs (Fig. 2-3). Nutrient plant proteins 
contain much less of both EAAs and LKTV than coronaviruses or human and animal proteins (Figures 2-3).

Table 2. Four EAAs content ( $\mathrm{g}$ ) in $\mathbf{1 0 0} \mathrm{g}$ of total protein from different diets compared with recommended dietary allowance by WHO

\begin{tabular}{|l|c|c|c|c|c|}
\hline Amino acid & WHO & $\begin{array}{c}\text { Human } \\
\text { milk }\end{array}$ & $\begin{array}{c}\text { Meat- } \\
\text { eaters }\end{array}$ & Vegans & AD $^{*}$ \\
\hline Leucine & 5,9 & 9,6 & 6,13 & 4,33 & 7,75 \\
\hline Lysine & 4,5 & 6,9 & 5,01 & 2,82 & 6,69 \\
\hline Threonine & 2,3 & 4,4 & 2,99 & 2,19 & 3,84 \\
\hline Valine & 3,9 & 5,5 & 4,14 & 2,95 & 5,07 \\
\hline Sum LKTV & 16,6 & 26,4 & 18,27 & 12,29 & 23,35 \\
\hline Ref. & {$[37]$} & {$[37]$} & {$[45]$} & {$[45]$} & {$[44]$} \\
\hline
\end{tabular}

AD* =Standard American Diet,

The spike protein and other structural polypeptides of coronaviruses contain a lot of leucine, threonine and valine [64], but less than the nonstructural polyproteins. Polyproteins of coronaviruses are synthesized at first [29-30] and are more than 45\% composed of EAAs (Fig. 4). The Ppla polyprotein of HCoV-OC43 and HCoV-HKU1 viruses contains much more EAAs than the homologous protein of SARS-CoV-2, SARS-CoV1 and MERS-CoV viruses (Fig. 4). The Ppla polyprotein of the HCoV-HKU1 virus is almost half composed of EAAs residues. Another feature of the proteins of $\mathrm{HCoV}$ viruses is the high content of four LKTV amino acid residues, almost 1/3 of all AAs (Fig. 2-3). SARS-CoV-2 coronavirus proteins contain more valine and threonine than alveolar cells [65] and other structural HCoV proteins (Fig. 5). The content of EAAs is highest in the Pp1a polyprotein (Fig. 4).

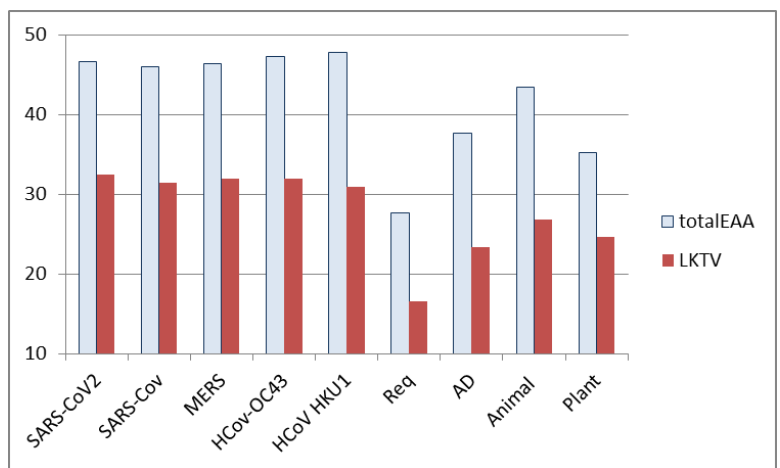

Fig. 2. Amount of EAAs in proteins from human beta-coronaviruses, animal and plants

Red: LKTV, light blue: total EAAs. AD: standard American Diet [44]. Animal: mean from meat, milk and egg products [40]. Plant: mean from rice, wheat, potato and soya [40]. Req: amount of EAAs required per day [1,37]. For HCoV protein sequences used means of Pp1ab+Spike which UniProtKB-ID listed in Table S2. On the ordinate axis indicated amount of EAAs as percentage of the total protein.

Vegans consume only half as much lysine as meat eaters (Table 2) [37]. The SARS-CoV-2 virus Ppla polyprotein contains 2-3 times more threonine or valine than consumed proteins (Fig. 5).

The Ppla proteins of HCoV-OC43 and HCoV-HKU1 contain twice as much valine as mammalian tissues (Fig. 5). The highest content of threonine is in Pp1a of the SARS-CoV-2 virus (Fig. 5). A significant amount of leucine (more than 9\%) is found in all five pathogenic HCoV viruses. The proteinogenic amino acid leucine has been noted to increase protein synthesis $[48,56,66]$. The SARS-CoV-2 virus causes metabolic reprogramming of the AAs profile, and competition between host and pathogen for EAAs is not excluded [21,23,62,67]. AAs deficiency inhibits translation [56], leucine deficiency inhibits the formation of intracellular polysomes [66]. 
Table 3. Content of selected EAAs in blood plasma, human tissues and diet proteins

Meat and Plant: average composition (\%) of EAAs in ingested $100 \mathrm{~g}$ dietary meat and plant products (Table 1).

\begin{tabular}{|l|c|c|c|c|c|c|c|}
\hline \multirow{2}{*}{ Amino acid } & \multicolumn{3}{|c|}{ Plasma AAs $[\mu \mathrm{mmol} / \mathrm{L}]$} & \multicolumn{4}{c|}{ \% of total protein } \\
\cline { 2 - 8 } & $\begin{array}{c}\text { Reference } \\
\text { intervals }\end{array}$ & $\begin{array}{c}\text { Meat- } \\
\text { eaters }\end{array}$ & Vegan & $\begin{array}{c}\text { Human } \\
\text { body }\end{array}$ & $\begin{array}{c}\text { Human } \\
\text { muscle }\end{array}$ & Meat & Plant \\
\hline Leucine & $66-170$ & 205 & 191 & 7,5 & 7,6 & 8,1 & 7,2 \\
\hline Lysine & $150-220$ & 241 & 210 & 7,3 & 7,8 & 9,0 & 4,5 \\
\hline Threonine & $92-240$ & 164 & 165 & 4,2 & 3,4 & 4,4 & 3,6 \\
\hline Valine & $150-310$ & 230 & 217 & 4,9 & 5,1 & 5,3 & 5,2 \\
\hline Ref. & $*$ & {$[45]$} & {$[45]$} & {$[37]$} & {$[41]$} & {$[40-41]$} & {$[40-41]$} \\
\hline
\end{tabular}

*https://www.ucsfhealth.org/

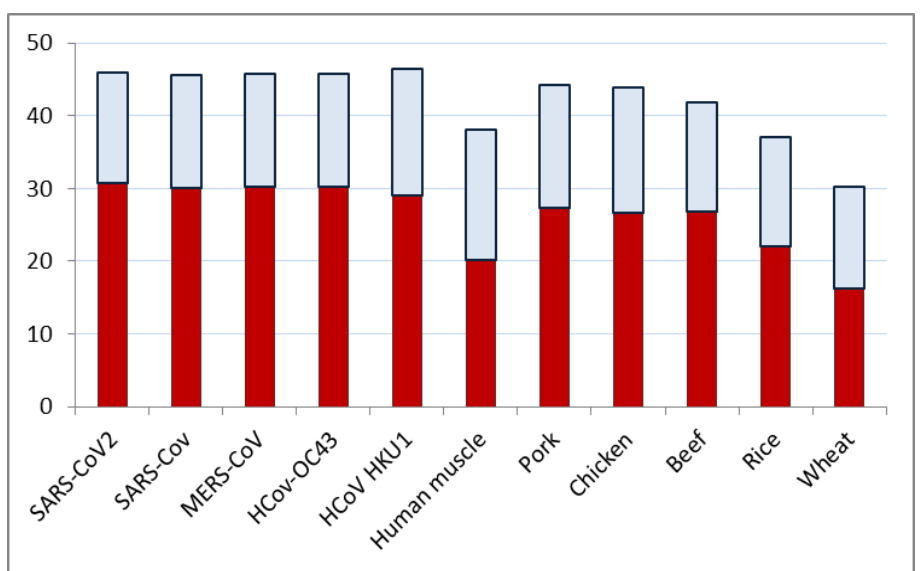

Fig. 3. Amount of EAAs in proteins from human beta-coronaviruses, animal and plants

Red: LKTV, light blue: the rest EAAs of total protein. For HCoV proteins used means of Pp1ab+Spike which UniProtKB-ID listed in Table S2. Human muscle: ratio EAAs, \% of total protein in human muscle [41]. On the ordinate axis indicated amount of AAs as percentage of the total protein.

\section{SARS-CoV-2 reproduction and translation kinetics}

The kinetics of reproduction of viruses, as well as other microorganisms, obeys the Monod equation, which is similar to the dependence of Michaelis-Menten on the concentration of the substrate for the enzymatic reaction [24-25]. Both of these equations describe the reaction rate as a function of substrate concentration. At a saturated concentration of translation substrates sufficient for the optimal rate of pathogen protein synthesis, virion replication passes through the lag phase and the fast phase into the exponential growth phase [24-25]. The doubling time of the SARS-CoV-2 virus is 6-10 hours [24,36]. Each pneumocyte can produce about a thousand new virions [36]. At the peak of infection in the body of an infected patient, the total number of viral particles reaches $10^{9}-10^{11}$ with a mass greater than $100 \mathrm{~g}$ [36]. As a result of successful reproduction of the SARS-CoV-2 virus, lung weight increases, but the total body weight of animals [68] or humans [7] decreases.

The expression rate of viral polypeptides rapidly increases after the lag phase [18,24-25]. The polypeptides of the SARS-CoV-2 virus are elongated by 6 amino acid residues per second [36]. For the log phase of protein synthesis, it is necessary that the concentration of free and transportable AAs significantly exceed Km [69]. More than 60 mutations were found in Omicron variant B.1.1.529 (GSAI ID: R40B60_BHP_3321001247/2021) of the SARS-CoV-2 virus, as a result of which the content of EAAs changed. This led to an alteration in the development dynamics of this pathogen [70]. 
The huge difference between the need and availability of LKTV makes them the first limiting substrates in the polymerization reaction of $\mathrm{HCoV}$ polypeptides. A reasonably high concentration of LAAs is required to enter the exponential phase of the synthetic reaction. A lack of even one amino acid can slow down or interrupt the translation of coronavirus polyproteins [43] and, therefore, a low concentration of LAAs blocks the synthesis of nonstructural polyproteins.

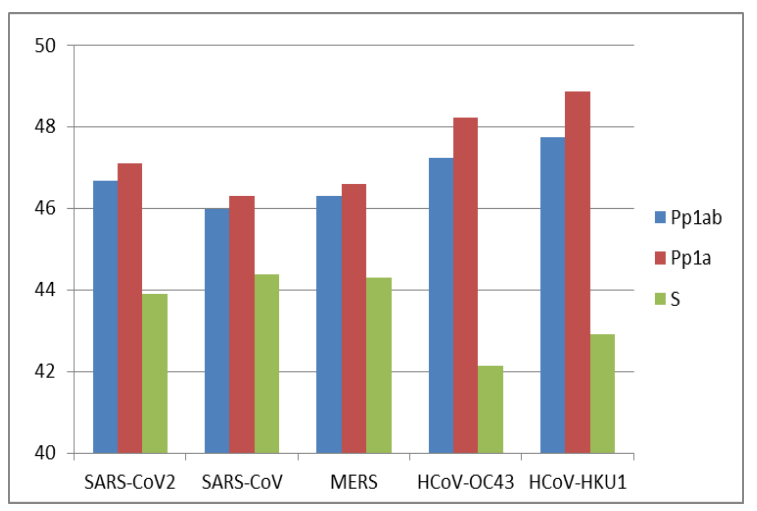

Fig. 4. Ratio of total EAAs in five HCoV proteins

Total amount of EAAs in proteins (\%) of Pp1a, Pp1ab and Spike protein of HCoV, which UniProtKB-ID listed in Table S2. On the ordinate axis indicated amount of AAs as percentage of the total protein.

\section{Factors affecting the rate of translation of SARS-CoV-2 polypeptides}

The HCoV-HKU1 virus contains more EAAs than the three SARS-causing pathogens and has more than $10 \%$ valine in its Pp1a polypeptide (Fig. 2-3,5). The lack of EAAs will lead to the interruption of the Pp1a translation, which is known to be synthesized as the first in HCov [2930]. Inhibition of translation of functional Pp1a and Pp1ab polypeptides can consequently lead to a radical decrease in the rate of synthesis of coronavirus gRNA and subgenomic RNA and the polypeptides they encode. Such a decrease in the rate of synthesis of Pp1a molecules or abortive translation can prevent the development of the log phase of replication, reduce the pathogenic effect of the virus, and prevent cytokine storm in COVID-19 patients.

The high concentration of EAAs in the polyproteins Pp1a and Pp1ab and, especially, the high requirement for valine, may explain the less severe outcome of infection with the two human coronaviruses HCoV-OC43 and HCoV-HKU1 compared to COVID-19.

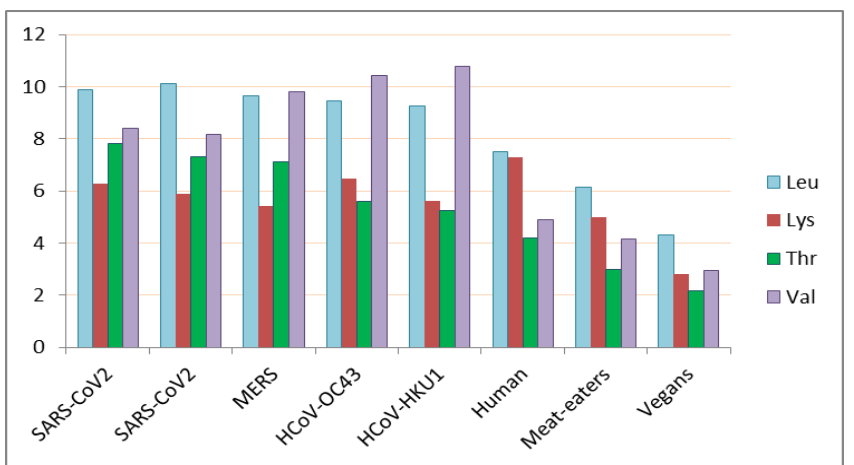

Fig. 5. Content of selected EAAs as percentage of total protein

Human: \% of EAAs in whole body [37]. Meat-eaters and Vegans: composition (\%) of EAA in ingested $100 \mathrm{~g}$ food proteins by meat-eaters or vegans [45]. For $\mathrm{HCoV}$ used sequence of polyprotein Pp1a which UniProtKB-ID listed in Table S2. On the ordinate axis indicated amount of AAs as percentage of the total protein. 
Table 4. Conditions for fast replication of SARS-CoV-2 virus in pneumocytes

\begin{tabular}{|c|c|}
\hline $\begin{array}{c}\text { Drivers of translation and } \\
\text { replication }\end{array}$ & Factors promoting viral protein synthesis \\
\hline $\begin{array}{l}\text { Intracellular structures and } \\
\text { mechanisms providing a high } \\
\text { rate of viral protein synthesis. }\end{array}$ & $\begin{array}{l}\text { The ability of PT2 to form transcriptional-translational complexes inside } \\
\text { membrane vesicles supplies a high rate of synthesis of gRNA and } \\
\text { subgenomic RNAs of the SARS-CoV-2 virus [36,73-74]. } \\
\text { The ability of PT2 to a high rate of protein synthesis provides a highly } \\
\text { developed rER and amino acid transport ATPases [69,73-76]. } \\
\text { A large number of mitochondria and a saturated oxygen concentration in } \\
\text { PT2 create good conditions for enhanced oxidative phosphorylation and } \\
\text { ensure high production of nucleoside triphosphates (NTP) and other } \\
\text { energy-rich molecules required for high-speed synthesis of RNA and } \\
\text { polypeptides increasing virus titer and lungs mass [7,68]. }\end{array}$ \\
\hline $\begin{array}{l}\text { SARS-CoV-2 virus alters and } \\
\text { suppresses host protein synthesis }\end{array}$ & $\begin{array}{l}\text { Viral proteins inhibit the synthesis of host cell polypeptides. The SARS- } \\
\text { CoV-2 virus changes the properties of the synthesized host proteins, that } \\
\text { leads to an alteration in the cell cycle and RNA splicing }[34,60,67] \text {. }\end{array}$ \\
\hline $\begin{array}{l}\text { Timely sufficient and, } \\
\text { significantly higher than } \mathrm{Km} \text {, } \\
\text { concentrations of necessary } \\
\text { FAAs in cells at a low rate of } \\
\text { their degradation. } \\
\text { Prolonged high concentration of } \\
\text { EAAs in plasma and their active } \\
\text { transport into the cell. }\end{array}$ & $\begin{array}{l}\text { Deficiency of AAs in contrast to their excess amount causes inhibition of } \\
\text { intracellular translation and decreases of protein synthesis [47]. } \\
\text { In the cytosol of cells, the concentration of AAs is higher than in plasma } \\
\text { [47,52,71-72]. } \\
\text { The content of threonine and valine in lung cells is lower than in SARS- } \\
\text { CoV-2 proteins [65]. }\end{array}$ \\
\hline $\begin{array}{l}\text { Metabolic mechanisms capable } \\
\text { of accelerating translation on the } \\
\text { ribosomes of the cell }\end{array}$ & $\begin{array}{l}\text { It is known that leucine induces translation [56,66]. A high concentration } \\
\text { of FAAs in plasma activates the activity of anabolic hormones. Animal } \\
\text { proteins are more anabolic than ones of plant origin [43]. }\end{array}$ \\
\hline $\begin{array}{l}\text { The intake of AAs from the } \\
\text { intestine and from the } \\
\text { breakdown products of host own } \\
\text { proteins. Anabolic hormones } \\
\text { inhibit the breakdown of } \\
\text { proteins in the body; therefore, } \\
\text { in the postprandial period, the } \\
\text { role of eaten proteins for the } \\
\text { transport of AAs in the tissue } \\
\text { increases. }\end{array}$ & $\begin{array}{l}\text { AAs are accumulated in plasma and most of FAAs are transported to } \\
\text { tissues }[48,50] \text {. } \\
\text { The postprandial plasma concentration of AAs, including leucine, } \\
\text { increase for } 2-5 \text { hours }[48-49] \text {, depending on the composition of the food. } \\
\text { After a peak, they decrease back to base levels }[45,47] \text {. Anabolic } \\
\text { hormones not only stimulate protein synthesis, they inhibit protein } \\
\text { breakdown as well }[59,63] \text {. }\end{array}$ \\
\hline $\begin{array}{l}\text { Consumption of a large amount } \\
\text { of highly bioavailable foods } \\
\text { with a high content of } \\
\text { proteinogenic AAs. }\end{array}$ & $\begin{array}{l}\text { In the process of enzymatic digestion, a pool of FAAs is formed in the } \\
\text { blood stream, and the concentration of EEAs increases significantly with } \\
\text { a sufficient level of nutrition. A high concentration of FAAs is required } \\
\text { for accelerated synthesis of viral proteins [54]. }\end{array}$ \\
\hline $\begin{array}{l}\text { The basic concentration of } \\
\text { FAAs is clearly regulated by } \\
\text { complex systems, both at the } \\
\text { level of cell and total organism }\end{array}$ & $\begin{array}{l}\text { The bioavailability of AAs from animal proteins is higher than that from } \\
\text { plant proteins. Consumption of large amounts of animal proteins provides } \\
\text { a high content of EAAs, which leads to a high rate of polypeptide } \\
\text { synthesis in animal tissues. Plant based food contains minor amount of } \\
\text { EAAs and gives less postprandial increase of FAAs }[45,55] \text {. }\end{array}$ \\
\hline
\end{tabular}


In the Table 4 are structured the data, from which it follows that optimal conditions are created in pneumocytes type 2 (PT2) for the synthesis of proteins of the SARS-CoV-2 virus. In the cells of the alveoli, a high level of protein expression was observed. The interaction of the synthesizing systems of the cell and the virus can provide high-speed translation on host ribosomes (Table 4). A high rate of viral protein synthesis is necessary for a short replication cycle and efficient production of a large population of progeny virions. The amount of LKTV may be the immediate primary limiting factor in the rate of translation of polypeptides, and hence the replication of the SARS-CoV-2 virus. The high requirement of Ppla coronavirus proteins for EAAs makes their replication very sensitive, especially to the lack of LKTV. Such lack of LAAs leads to inhibition of SARS-CoV-2 virus replication or even to unproductive infection.

\section{Conclusions}

By the end of 2021, the COVID-19 pandemic had gone through five global waves of infection and has entered the sixth one [1-3]. The number of registered infected patients in the world exceeded 378 million, with more than 5.7 million deaths [1-3]. In $20 \%$ of those who have been infected, long-term post-COVID complications developed [1-2,5].

SARS-CoV-2 is a large, highly organized coronavirus that is transmitted from person to person by airborne droplets and causes COVID-19 disease [1-2, 5]. So far, no reliable data have been obtained on the effective use of an etiological drug that suppresses the early translation of the proteins of this pathogenic virus [4-5,30-31].

For the successful reproduction of viruses, an optimal pathogen-host relationship is required. The virus, as an obligate parasite, uses various cellular machinery and building elements to synthesize its structural and functional components. For the synthesis of viral proteins, a pool of free amino acids of the cell is used.

Homeostasis of AAs in mammalian cells and organisms have been skillfully investigated $[37,47,66]$. In cells and organisms well-organized regulatory mechanisms to maintain a homeostatic intracellular and extracellular FAAs composition were created during evolution. AAs homeostasis in mammal's body or cells is controlled through regulation of protein intake, absorption, transport and utilization of AAs and proteins biosynthesis, reprocessing and degradation. Entry and metabolism pathways of AAs are directed by the CNS and metabolic hormones. There are many AAs transporters, anti-porters and symporters assisting to entry into cells or exit them [47]. AAs are accumulated in the cytosol with concentration higher than concentration of plasma FAA [47,71-72].

Diet is one of the important factors in the development of infectious pathogenesis [6-13]. In a large statistical sample (Table S1), as in other types of representative samples [15], high animal protein intake has been shown to be directly correlated with dangerous COVID-19 disease outcomes. The predominant consumption of plant products reduces the risks of the damaging pathogenesis process of this infectious disease $[15,17]$. Plants due high presence of anti-nutritional factors are less bioavailable or anabolic than animal proteins $[43,45,55]$. Some food plants produce a large number of protease inhibitors, that are capable to reduce the postprandial intake of free amino acids in the blood plasma [15,58,77-79].

Animal dietary proteins contain much more EAAs than plant proteins (Table 1, Figs. 1-3) [40-41]. People who consume a predominantly plant-based products have less EAAs in their plasma compared to meat-eaters [45-46,55]. Part of the EAAs stimulates anabolic processes, and leucine directly increases the synthesis of proteins in cells [56-57,59].

During the infectious process, the metabolism of the host cells changes. Apparently, the high need of SAR-CoV-2 virions for some EAAs leads to the detected imbalance of the amino acid profile not only in cells, but throughout the host organism [18-23]. The SARS-CoV-2 pathogen changes the profile and competes for EAAs fluxes, and also suppresses the synthesis of the host cell's proteins $[5,34,60-62,67]$. Metabolic data of infected patients are unique and are a vital help to investigate the dynamics of pathogenesis, to forecast severe cases, and to adapt therapy [61]. 
The SARS-2 virus contains many more EAAs than animal tissue (Fig. 2-3). Plant staple foods contain two to three times less of some EAAs than coronavirus proteins (Table 1-2, Fig. 5). Analysis of the molecular structure of coronaviruses showed a high requirement of these pathogens for the four dietary EAAs namely LKTV (Fig. 2-5). From this it follows that a deficiency of LKTV can lead to a significant decrease in the rate of early polypeptide synthesis or to terminate translation of polyproteins. The highest content of these four EAAs is in the nonstructural polyprotein Pp1a of coronaviruses (Fig. 4). This polypeptide contains several tripeptidyls and dozens of dipeptidyls of LKTV amino acid residues [32-33]. The polyproteins Pp1a and Pp1ab contain more of these four amino acids than the structural proteins of HCoV (Fig. 4) $[32,65]$. The content of threonine and valine in SARS-CoV-2 virus proteins is higher than in lung cells [65]. A radical decrease in the rate of early translation of polypeptides will slow down the rate of virus replication, which can lead to abortive reproduction, as well as a timely and successful physiological response of the immune system. The SARS-CoV-2 mutant Omicron B.1.1.529 contains more essential amino acids than the null variant $[32-33,70]$, which changed the pathogenicity of the virus.

The concentration of free EAAs in the bloodstream is increased due to their high bioavailability. An increased concentration of EAAs is an important positive factor for the rate of protein synthesis and non-stop replication of the SARS-CoV-2 virus. This may explain the very high rates of COVID-19 morbidity and mortality in regions with excess consumption of animal proteins (Table S1) [14-15].

Protein synthesis is regulated by a cascade of enzymatic reactions, whose rate is determined by the Michaelis-Menten equation. The coefficient $\mathrm{Km}$ is defined as the concentration of substrate at half maximal velocity (Vmax) of the enzymatic reaction. A great quantity of FAAs in contrast to their reduction presents a molecular mechanism of intracellular fast translation [47]. Biochemical analysis showed that optimal conditions were created in human pneumocytes for the rapid production of a huge amount of SARS-CoV-2 virions (Table 4). For pneumocytes, high Km for AAs transport ATPases were established [69]. Table 4 analyzes the factors that provide a high rate of protein synthesis of the SARS-CoV-2 virus. It follows from the analysis that intracellular mechanisms and conditions, as well as the high availability of dietary EAAs, can ensure the translation rate into the exponential phase. Therefore, in order to inhibit the viral replication cycle at an early stage of infection, an infected person needs to consume foods that contain much fewer limiting amino acids compared to the proteins of the SARS-CoV-2 virus.

The conducted analysis (Table S1,4) answers the question: why in some low-income countries in Africa and Asia are minimal COVID-19 burden despite substantial global circulation of the SARS-CoV-2 virus [14-15,80].

That is, diet can reduce the replication rate of the SARS-CoV-2 virus and its cytopathic effect; contribute to the inhibition of pathogenesis at an early stage of infection, thereby reducing the destructive effect of COVID-19 and moderate mortality. Therefore, in the initial stage of infection with the pathogenic SARS-CoV-2 virus, the amount of food consumed should be limited, since it is important to eat and absorb sugars, fats and animal proteins in an amount and proportion not exceeding the vital volume (Table2, Fig. 2).

\section{Resolutions}

SARS-CoV-2 coronavirus causes COVID-19 disease in humans. The pandemic of this infectious disease has been depressing the vital activity of all mankind for almost two years. Effective methods are urgently needed to combat COVID-19.

The relationship between diet type and the impact of the COVID-19 pandemic in the top 20 countries by number of infections has been explored using numerous available statistics. A 
positive correlation between the severity of COVID-19 outcome and animal protein intake has been identified previously for many countries and regions and confirmed by the latest analysis. The SARS-CoV-2 virus interacts with human ACE2 receptors, multiplies rapidly in affected cells, and critically alters proteinostasis and amino acid homeostasis in the host organism.

Coronaviruses, after invasion into the cell, must first of all translate the polyproteins Pp1a and Pplab. These polypeptides of coronaviruses, unlike the proteins of the human body, other animals and plants, contain a very high amount of EAAs. The proportion of EAAs is the highest in the Ppla polyprotein, namely $47 \%$ in the SARS-CoV-2 virus. Almost one third of the total amino acid composition of Ppla is represented by four EAAs: leucine; lysine; threonine and valine. The limited availability of one of these substrate elements can lead to a disruption in the polymerization rate of the Pp1a and Pp1ab polypeptide chains and, subsequently, to inhibition of SARS-CoV-2 virus early stage of replication.

EAAs are not synthesized de novo in the human body. The most of EAAs enters all tissues of the body from food. With a low-calorie diet, and a predominantly plant-based diet, a small amount of EAAs enters the bloodstream. Such a deficiency of four limiting EAAs can block the transition to the exponential phase of the rate of early viral protein synthesis, which leads to a slowdown in the reproduction of the pathogen or to an abortive SARS-CoV-2 infection.

It should be noted that protein intake below the WHO recommendation does not protect against the spread or infection and invasion of viral particles. In regions where diets are predominantly low in these LAAs, infected patients may have asymptomatic or mild COVID-19 disease, without post-COVID syndrome.

Comparison of the AAs composition of the SARS-CoV-2 pathogen and the host showed that LKTV are limiting for the synthesis of Ppla and Pp1ab virus polyproteins. This analysis explains the statistically low rates of COVID-19 cases, as well as ease of outcomes, in countries with lower recommended intakes of total protein and, especially, foods deficient in these EAAs.

Acknowledgement

Many thanks to Dr. Stefan Hermann for the critical reading of the manuscript.

Cordially thanks to my family for their continual support.

I dedicate this article to the anniversary birthday of my son Alexander

\section{References}

1. World Health Organization. https://www.who.int

2. COVID-19. https://www.cdc.gov/coronavirus/2019-ncov/ Accessed: 10.09.2021.

3.https://www.worldometers.info Accessed: 31.01.2022

4. Mei M., Tan X. Current Strategies of Antiviral Drug Discovery for COVID-19. Front Mol

Biosci. 2021; 8: 671263. doi: 10.3389/fmolb.2021.671263. Accessed: 31.01 .2022

5. Yapasert R., Khaw-On P., Banjerdpongchai R. Coronavirus Infection-Associated Cell Death Signaling and Potential Therapeutic Targets. Molecules. 2021; 26(24): 7459.

doi:10.3390/molecules26247459 Accessed: 31.01.2022

6. Allard L., Ouedraogo E., Molleville J., et al. Malnutrition: Percentage and Association with Prognosis in Patients Hospitalized for Coronavirus Disease 2019. Nutrients. 2020; 12(12): 3679. https://doi: 10.3390/nu12123679.

7. Bedock D., Couffignal J., Bel Lassen P., et al. Evolution of Nutritional Status after Early Nutritional Management in COVID-19 Hospitalized Patients. Nutrients. 2021; 13: 2276. https:// doi.org/10.3390/nu13072276

8. Clemente-Suárez V.J., Ramos-Campo D.J., Mielgo-Ayuso J., et al. Nutrition in the Actual COVID-19 Pandemic. A Narrative Review. Nutrients. 2021; 13: 1924.

https://doi.org/10.3390/ nu13061924 
9. James P.T., Ali Z., Armitage A.E., et al. The Role of Nutrition in COVID-19 Susceptibility and Severity of Disease: A Systematic Review. J Nutr. 2021; 151(7): 1854-1878. doi: 10.1093/jn/nxab059. Accessed: 20.08.2021

10. Mentella M.C., Scaldaferri F., Gasbarrini A., Miggiano G.A.D. The Role of Nutrition in the COVID-19 Pandemic. Nutrients. 2021; 13: 1093. https://doi.org/10.3390/nu13041093

11. Mechanick J.I., Carbone S., Dickerson R.N., et al. Clinical Nutrition Research and the COVID-19 Pandemic: A Scoping Review of the ASPEN COVID-19 Task Force on Nutrition Research. J Parenter Enteral Nutr. 2021; 45(1): 13-31. doi:10.1002/jpen.2036

12. Morais A., Aquino J. S., da Silva-Maia J. K., et al. Nutritional status, diet and viral respiratory infections: perspectives for severe acute respiratory syndrome coronavirus 2 . British J.Nutrition. 2021; 125(8): 851-862. https://doi.org/10.1017/S0007114520003311

13. Mortaz E., Bezemer G., Alipoor S.D., et al. Nutritional Impact and Its Potential Consequences on COVID-19 Severity. Front. Nutr. 2021; 8:698617. doi:10.3389/fnut.2021.698617 Accessed: 20.08.2021

14. Ponomarenko S. Economic and social factors affecting the epidemiological process of the SARS-CoV-2 coronavirus. COVID19-PREPRINTS.MICROBE.RU. 2021. https://covid19preprints.microbe.ru/files/320 Accessed: Accessed: 31.01 .2022

15. Ponomarenko S. The development and outcomes of the COVID-19 disease correlate with the type of nutrition COVID19-PREPRINTS.MICROBE.RU. 2021. https://covid19-preprints.microbe.ru/files/341 Accessed: 31.01 .2022

16. Wu G. Dietary protein intake and human health. Food Funct. 2016; 7, 1251-1265

17. Kim H., Rebholz C.M., Hegde S., et al. Plant-based diets, pescatarian diets and COVID-19 severity: a population-based case-control study in six countries. BMJ Nutrition, Prevention \& Health. 2021; doi:10.1136/bmjnph-2021-000272 Accessed: 20.08.2021

18. Aller S., Scott A., Sarkar-Tyson M., Soyer O.S. Integrated human virus metabolic stoichiometric modelling predicts host-based antiviral targets against Chikungunya, Dengue and Zika viruses. J. R. Soc. Interface. 2018; 15: 20180125. http://dx.doi.org/10.1098/rsif.2018.0125

19. Bojkova D., Klann K., Koch B., et al. Proteomics of SARS-CoV-2-infected host cells reveals therapy targets. Nature. 2020; 583(7816): 469-472. doi: 10.1038/s41586-0202332-7.

20. Delattre H., Sasidharan K., Soyer O.S. Metabolic inhibition of SARS-CoV-2. Life Science Alliance. 2020, 4 (1) e202000869; DOI: 10.26508/lsa.202000869 Accessed:11.11.2021

21. Mussap M., Fanos V. Could metabolomics drive the fate of COVID-19 pandemic? A narrative review on lights and shadows. CCLM. 2021, pp. 000010151520210414. https://doi.org/10.1515/cclm-2021-0414

22. Páez-Franco J.C., Torres-Ruiz J., Sosa-Hernández V.A. et al. Metabolomics analysis reveals a modified amino acid metabolism that correlates with altered oxygen homeostasis in COVID-19 patients. Sci Rep. 2021; 11, 6350. https://doi.org/10.1038/s41598-02185788-0

23. Wu J, Zhao M, Li C, Zhang Y, Wang DW. The SARS-CoV-2 induced targeted amino acid profiling in patients at hospitalized and convalescent stage. Biosci Rep. 2021; 41(3): BSR20204201. doi: 10.1042/BSR20204201.

24. Cheemarla N.R., Watkins T.A., Mihaylova V.T., et al. Dynamic innate immune response determines susceptibility to SARS-CoV-2 infection and early replication kinetics. $J$ Exp Med. 2021; 218 (8): e20210583. https://doi.org/10.1084/jem.20210583

25. Pyke A.T., Nair N., van den Hurk A.F., et al. Replication Kinetics of B.1.351 and B.1.1.7 SARS-CoV-2 Variants of Concern Including Assessment of a B.1.1.7 Mutant Carrying a Defective ORF7a Gene. Viruses. 2021; 7; 13(6):1087. doi: 10.3390/v13061087. 
26. Abdelrahman Z., Li M., Wang X. Comparative Review of SARS-CoV-2, SARS-CoV, MERS-CoV, and Influenza A Respiratory Viruses. Front. Immunol. 2020; 11: 552909. doi: 10.3389/fimmu.2020.552909 Accessed: 20.08.2021

27. Hu B., Guo H., Zhou P. et al. Characteristics of SARS-CoV-2 and COVID-19. Nat Rev Microbiol. 2021; 19: 141-154. https://doi.org/10.1038/s41579-020-00459-7

28. To K. K., Sridhar S., Chiu K. H., et al. Lessons learned 1 year after SARS-CoV-2 emergence leading to COVID-19 pandemic. Emerging microbes \& infections. 2021; 10(1): 507-535. https://doi.org/10.1080/22221751.2021.1898291

29. V'kovski, P., Kratzel, A., Steiner, S. et al. Coronavirus biology and replication: implications for SARS-CoV-2. Nat Rev Microbiol. 2021; 19: 155-170. https://doi.org/10.1038/s41579-020-00468-6

30. Yadav R., Chaudhary J.K., Jain N. et al. Role of Structural and Non-Structural Proteins and Therapeutic Targets of SARS-CoV-2 for COVID-19. Cells. 2021; 10(4): 821. doi: 10.3390/cells 10040821.

31. Yoshimoto F.K. The Proteins of Severe Acute Respiratory Syndrome Coronavirus-2 (SARS CoV-2 or n-COV19), the Cause of COVID-19. Protein Journal. 2020; 39:198216 https://doi.org/10.1007/s10930-020-09901-4

32. https://www.ncbi.nlm.nih.gov/

33. https://www.uniprot.org/uniprot/

34. Finkel Y., Gluck A., Nachshon A. et al. SARS-CoV-2 uses a multipronged strategy to impede host protein synthesis. Nature. 2021; 594, 240-245.

https://doi.org/10.1038/s41586-021-03610-3

35. Bhatt P.R., Scaiola A., Loughran G., et al. Structural basis of ribosomal frameshifting during translation of the SARS-CoV-2 RNA genome. SCIENCE. 2021; 372; 6548, 13061313. DOI: $10.1126 /$ science.abf3546

36. Bar-On Y.M., Flamholz A., Phillips R., Milo R. SARS-CoV-2 (COVID-19) by the numbers. eLife. 2020; 9, e57309.

37. Joint WHO/FAO/UNU Expert Consultation. Protein and amino acid requirements in human nutrition. World Health Organ Tech Rep Ser. 2007; 935: 1-265 p.

38. https://ourworldindata.org Accessed: 20.07.2021.

39. New Food Balances. Available at: https://FAO.org/faostat/en/\#data/FBS Accessed: 20.07.2021

40. Gardner C.D., Jennifer C Hartle J.C., et al. Maximizing the intersection of human health and the health of the environment with regard to the amount and type of protein produced and consumed in the United States, Nutrition Reviews. 2019; 77; 4, 197-215 https://doi.org/10.1093/nutrit/nuy073

41. Gorissen S.H.M., Crombag J.J.R., Senden J.M.G. et al. Protein content and amino acid composition of commercially available plant-based protein isolates. Amino Acids. 2018; 50, 1685-1695. https://doi.org/10.1007/s00726-018-2640-5

42. Kang J.-S. Dietary restriction of amino acids for Cancer therapy. Nutrition \& Metabolism. 2020; 17:20 https://doi.org/10.1186/s12986-020-00439-x

43. Verzola D., Picciotto D., Saio M., et al. Low Protein Diets and Plant-Based Low Protein Diets: Do They Meet Protein Requirements of Patients with Chronic Kidney Disease? Nutrients. 2021; 13: 83. https://doi.org/10.3390/nu13010083

44. Paul C., Leser S., Oesser S. Significant Amounts of Functional Collagen Peptides Can Be Incorporated in the Diet While Maintaining Indispensable Amino Acid Balance. Nutrients. 2019; 11; 5, 1079; https://doi.org/10.3390/nu11051079

45. Schmidt J., Rinaldi S., Scalbert A. et al. Plasma concentrations and intakes of amino acids in male meat-eaters, fish-eaters, vegetarians and vegans: a cross-sectional analysis in the EPIC-Oxford cohort. Eur J Clin Nutr. 2016; 70, 306-312.

https://doi.org/10.1038/ejcn.2015.144 
46. Mariotti F., Gardner C.D. Dietary Protein and Amino Acids in Vegetarian Diets-A Review. Nutrients. 2019; 11; 11: 2661. doi:10.3390/nu11112661 Accessed: 07.10.2021

47. Bröer S., Bröer A. Amino acid homeostasis and signaling in mammalian cells and organisms. Biochem J. 2017; 474; 12: 1935-1963. https://doi.org/10.1042/BCJ20160822

48. Groen B.B.L., Horstman A.M., Hamer H.M., et al. Post-Prandial Protein Handling: You Are What You Just Ate. PLoS ONE. 2015; 10; 11: e0141582. doi:10.1371/ journal.pone.0141582

49. Horstman A.M.H., Ganzevles R.A., Kudla U., et al. Postprandial blood amino acid concentrations in older adults after consumption of dairy products: The role of the dairy matrix. https://doi.org/10.1016/j.idairyj.2020.104890

50. Trommelen J., Tome D., van Loon L. C. Gut amino acid absorption in humans: Concepts and relevance for postprandial metabolism. Clinical Nutrition Open Science 2021; 36: 43e55 DOI: https://doi.org/10.1016/j.nutos.2020.12.006

51. Atila A., Alay H., Yaman M.E. et al. The serum amino acid profile in COVID-19. Amino Acids. 2021. https://doi.org/10.1007/s00726-021-03081-w Accessed: 10.01.2022

52. Holeček M. The role of skeletal muscle in the pathogenesis of altered concentrations of branched-chain amino acids (valine, leucine, and isoleucine) in liver cirrhosis, diabetes, and other diseases. Physiol Res. 2021; 70; 3: 293-305. doi: 10.33549/physiolres.934648.

53. Yamamoto H, Kondo K., Tanaka T., et al. Reference intervals for plasma-free amino acid in a Japanese population. Ann. Clin. Biochemistry. 2016; 53; 3: 357-364

54. Ren W., Rajendran R., Zhao Y., et al. Amino Acids As Mediators of Metabolic Cross Talk between Host and Pathogen. Front. Immunol. 2018; 9:319. doi:10.3389/fimmu.2018.00319

55. Purpura M., Lowery R.P., Joy J.M., et al. A Comparison of Blood Amino Acid Concentrations Following Ingestion of Rice and Whey Protein Isolate: A Double-Blind Crossover Study. J Nutr Health Sci. 2014; 1; 3: 306

56. Sans M.D., Crozier S.J., Vogel N.L. Dietary Protein and Amino Acid Deficiency Inhibit Pancreatic Digestive Enzyme mRNA Translation by Multiple Mechanisms. Cell Mol Gastroenterol Hepatol. 2021; 11; 1: 99-115. doi: 10.1016/j.jcmgh.2020.07.008.

57. Wilkinson D.J., Bukhari S.S.I., Phillips B.E., et al. Effects of leucine-enriched essential amino acid and whey protein bolus dosing upon skeletal muscle protein synthesis at rest and after exercise in older women. Clin Nutr. 2018; 37(6 Pt A):2011-2021. doi: 10.1016/j.clnu.2017.09.008.

58. Yang Y., Churchward-Venne T.A., Burd N. A., et al. Myofibrillar protein synthesis following ingestion of soy protein isolate at rest and after resistance exercise in elderly men. Nutrition \& Metabolism. 2012; 9:57. 10.1113/jphysiol.2003.050674.

59. Bohé J., Low A., Wolfe R.R., et al. Human muscle protein synthesis is modulated by extracellular, not intramuscular amino acid availability: a dose-response study. J Physiol. 2003; 552(Pt 1): 315-24. doi: http://www.nutritionandmetabolism.com/content/9/1/57

60. Banerjee A.K., Blanco M.R., Bruce E.A., et al. SARS-CoV-2 Disrupts Splicing, Translation, and Protein Trafficking to Suppress Host Defenses. Cell. 2020; 183(5): 13251339.e21. doi: 10.1016/j.cell.2020.10.004.

61. Shi D, Yan R, Lv L, et al. The serum metabolome of COVID-19 patients is distinctive and predictive. Metabolism. 2021;118:154739. doi:10.1016/j.metabol.2021.154739

62. Rees C.A., Rostad C.A., Mantus G. et al. Altered amino acid profile in patients with SARS-CoV-2 infection. Proc Natl Acad Sci USA. 2021; 118: 25 e2101708118; DOI: 10.1073/pnas.2101708118 Accessed:11.11.2021

63. Bart van Sloun B., Goossens G.H., Erdos B., et al. The Impact of Amino Acids on Postprandial Glucose and Insulin Kinetics in Humans: A Quantitative Overview. Nutrients. 2020; 12, 3211; doi:10.3390/nu12103211 
64. Renz A., Widerspick L., Dräger A. Genome-Scale Metabolic Model of Infection with SARS-CoV-2 Mutants Confirms Guanylate Kinase as Robust Potential Antiviral Target. Genes (Basel). 2021; 12(6): 796. doi: 10.3390/genes12060796.

65. Renz A., Widerspick L., Dräger A. FBA reveals guanylate kinase as a potential target for antiviral therapies against SARS-CoV-2. Bioinformatics. 2020; 36, Issue Supplement_2, Pages i813-i821, https://doi.org/10.1093/bioinformatics/btaa813

66. Mazor K.M., Dong L., Mao Y., et al. Effects of single amino acid deficiency on mRNA translation are markedly different for methionine versus leucine. Scientific Report. 2018; 8:8076 | DOI:10.1038/s41598-018-26254-2

67. Lapointe C.P., Grosely R., Johnson A.G., et al. Dynamic competition between SARSCoV-2 NSP1 and mRNA on the human ribosome inhibits translation initiation. Proc Natl Acad Sci USA. 2021; 118(6): e2017715118. doi: 10.1073/pnas.2017715118.

68. Cantwell A.M., Singh H., Platt M., et al. Kinetic multi-omic analysis of responses to SARS-CoV-2 infection in a model of severe COVID-19. J Virol. 2021; 95: e01010-21. https://doi.org/10.1128/JVI.01010-21.

69. Uchiyama T., Fujita T., Gukasyan H.J., et al. Functional characterization and cloning of amino acid transporter $\mathrm{B}^{0,+}\left(\mathrm{ATB}^{0,+}\right)$ in primary cultured rat pneumocytes. https://doi.org/10.1002/jcp.21254 Accessed: 10.01.2022

70. He X, Hong W, Pan X, Lu G, Wei X. SARS-CoV-2 Omicron variant: Characteristics and prevention. MedComm. 2021; 2(4):838-45. doi: 10.1002/mco2.110. Accessed: 10.01.2022

71. Bergström J., Fürst P., Norée L.O., Vinnars E. Intracellular free amino acid concentration in human muscle tissue. J. Appl. Physiol. 1974; 36, 693-697 PMID:4829908,

72. Hoffmann E.K., Lambert I.H. Amino acid transport and cell volume regulation in Ehrlich ascites tumour cells. J. Physiol. 1983; 338, 613-625 doi:10.1113/jphysiol.1983.sp014692

73. Fehrenbach H. Alveolar epithelial type II cell: defender of the alveolus revisited. BioMed Central Ltd (Print ISSN 1465-9921. 2001; Available online http://respiratoryresearch.com/content/2/1/033 Accessed: 10.01.2022

74. Knudsen, L., Ochs, M. The micromechanics of lung alveoli: structure and function of surfactant and tissue components. Histochem Cell Biol 150, 661-676 (2018). https://doi.org/10.1007/s00418-018-1747-9

75. Mason R.J. Biology of alveolar type II cells. Respirology. 2006; 11: S12-S15 https://onlinelibrary.wiley.com/doi/pdf/10.1111/j.1440-1843.2006.00800.x Accessed: 30.11 .2021

76. Weibel E.R. On the Tricks Alveolar Epithelial Cells Play to Make a Good Lung. Am J Respir Crit Care Med. 2015; 191; 5: 504-513, https://www.atsjournals.org/doi/pdf/10.1164/rccm. 201409-1663OE Accessed: 30.11.2021

77. Srikanth S., Chen Z. Plant Protease Inhibitors in Therapeutics-Focus on Cancer Therapy. Front. Pharmacol. 2016; 7; 470: 1-19. https://www.frontiersin.org/article/10.3389/fphar.2016.00470

78. Billinger E., Zuo Sh., Johansson G. Characterization of Serine Protease Inhibitor from Solanum tuberosum Conjugated to Soluble Dextran and Particle Carriers. ACS Omega. 2019; 4; 19: 18456-18464 https://doi.org/10.1021/acsomega.9b02815

79. Komarnytsky S., Cook A., Raskin I. Potato protease inhibitors inhibit food intake and increase circulating cholecystokinin levels by a trypsin-dependent mechanism. Int J Obes (Lond). 2011; 35(2): 236-243. doi: 10.1038/ijo.2010.192.

80. Wamai, R.G., Hirsch, J.L., Van Damme, W., et al. What Could Explain the Lower COVID-19 Burden in Africa Despite Considerable Circulation of the SARS-CoV-2 Virus?. Preprints 2021, 2021050549 doi: 10.20944/preprints202105.0549.v1. Accessed: 20.08.2021 


\section{Supplement Material}

Table S1. Relation between outcomes of the COVID-19 and diet factors in countries Top-20 infection cases from different continents, January 31, 2022

\begin{tabular}{|c|c|c|c|c|c|c|}
\hline \multirow[b]{2}{*}{ Country } & \multirow[b]{2}{*}{$\begin{array}{l}\text { Total Cases } \\
(\mathrm{mln})\end{array}$} & \multirow{2}{*}{\begin{tabular}{l}
\multicolumn{1}{c}{ Cases } \\
Cases/ 1T \\
population \\
(RPr)
\end{tabular}} & \multirow[b]{2}{*}{$\begin{array}{l}\text { Deaths/1T } \\
\text { population } \\
\text { (IFR) }\end{array}$} & \multicolumn{3}{|c|}{ Consumed protein g/ person/day } \\
\hline & & & & TP & AP & PP \\
\hline World & 378,903 & 48,6 & 0,73 & 81,2 & 32,1 & 49,1 \\
\hline USA & 76,222 & 228,1 & 2,72 & 113,7 & 73,9 & 39,9 \\
\hline India & 41,469 & 29,6 & 0,35 & 65,3 & 14,7 & 50,6 \\
\hline Brazil & 25,454 & 118,4 & 2,92 & 90,9 & 52,8 & 38,1 \\
\hline France & 19,140 & 292,2 & 2,00 & 112,1 & 69,7 & 42,4 \\
\hline UK & 17,315 & 253,0 & 2,28 & 104,0 & 58,5 & 45,6 \\
\hline Russia & 11,861 & 81,2 & 2,27 & 101,9 & 55,8 & 46,1 \\
\hline Turkey & 11,619 & 135,5 & 1,02 & 101,2 & 35,8 & 65,4 \\
\hline Italy & 10,983 & 182,1 & 2,43 & 106,8 & 57,0 & 49,7 \\
\hline Spain & 9,961 & 212,9 & 2,00 & 107,1 & 66,5 & 40,6 \\
\hline Germany & 9,896 & 117,5 & 1,41 & 104,2 & 63,1 & 41,1 \\
\hline Argentina & 8,378 & 182,7 & 2,64 & 106,1 & 65,7 & 40,4 \\
\hline Iran & 6,373 & 74,4 & 1,55 & 87,6 & 25,3 & 62,3 \\
\hline Colombia & 5,887 & 113,8 & 2,60 & 72,4 & 37,2 & 35,2 \\
\hline Mexico & 4,930 & 37,6 & 2,33 & 93,4 & 43,8 & 49,6 \\
\hline Poland & 4,886 & 129,3 & 2,78 & 103,1 & 55,4 & 47,7 \\
\hline Netherlands & 4,432 & 257,8 & 1,24 & 104,6 & 68,4 & 36,2 \\
\hline Indonesia & 4,353 & 15,7 & 0,52 & 68,6 & 22,2 & 46,4 \\
\hline Ukraine & 4,064 & 93,8 & 2,31 & 86,2 & 37,4 & 48,8 \\
\hline South Africa & 3,605 & 59,6 & 1,57 & 83,4 & 34,9 & 48,8 \\
\hline Philippines & 3,560 & 31,8 & 0,48 & 62,7 & 25,7 & 37,0 \\
\hline
\end{tabular}

Correlation coefficients

\begin{tabular}{lrr} 
& \multicolumn{2}{c}{$(\mathbf{r})$} \\
\multicolumn{1}{c}{ Factors } & \multicolumn{1}{c}{ RPr } & \multicolumn{1}{l}{ IFR } \\
IFR & 0,41 & \\
TP & 0,79 & 0,57 \\
AP & $\mathbf{0 , 8 3}$ & $\mathbf{0 , 6 1}$ \\
PP & $-\mathbf{0 , 3 0}$ & $\mathbf{- 0 , 2 4}$
\end{tabular}

Correlation between rate of prevalence (RPr) or infection fatality rate (IFR) of the SARS-CoV-2 infection and amount of consumed animal protein (AP), plant protein (PP), total protein (TP). AP, PP, TP in g/day/person [38-39].

$\mathrm{RPr}=$ amount registered infected persons/1000 population (31.01.2022) [3], IFR= amount registered COVID-19 deaths/1000 population (31.01.2022).

Below is a table with correlation coefficients (r) between COVID-19 outcomes and consumed diet proteins. 
Table S2. ID of HCoV Proteins from UniProtKB data base [33]

\begin{tabular}{llll} 
& \multicolumn{3}{c}{$\begin{array}{c}\text { Proteins } \\
\text { Pp1ab }\end{array}$} \\
Virus & Pp1a & Spike \\
\hline SARS-CoV-2 & P0DTC1 & P0DTD1 & P0DTC2 \\
SARS-CoV & P0C6U2 & P0C6X7-1 & P59594 \\
MERS-CoV & K9N638-1 & K9N7C7 & R9UQ53 \\
HCoV-OC43 & P0C6U7 & P0C6X6 & P36334 \\
HCoV-HKU1 & P0C6U3 & A0A3G2KXK3 & Q0ZME7
\end{tabular}

